\title{
Penerapan Metode Pembelajaran Diskusi Tipe Buzz Grup Untuk Meningkatkan Hasil Belajar Mahasiswa
}

\author{
${ }^{1}$ Kholida Ismatulloh, ${ }^{2}$ Khaerus Syahidi \\ ${ }^{1}$ Prodi Pendidikan Informatika, FMIPA, Universitas Hamzanwadi, Jln. TGKH. M. Zainuddin \\ Abdul Madjid No. 132 Pancor Selong, Lombok Timur, NTB, 83611 \\ ${ }^{2}$ Prodi Pendidikan Fisika, FMIPA, Universitas Hamzanwadi, Jln. TGKH. M. Zainuddin \\ Abdul Madjid No. 132 Pancor Selong, Lombok Timur, NTB, 83611
}

\section{EmailKorespondensi: kholida.ebtaryadi@gmail.com, khaerussyahidi@gmail.com}

\begin{tabular}{|c|c|}
\hline Article Info & bstract \\
\hline $\begin{array}{l}\text { Article History } \\
\text { Received: August } \\
\text { Revised: October } \\
\text { Published: December }\end{array}$ & \multirow{2}{*}{$\begin{array}{l}\text { The research title "The Implementation of Buzz Group Discussion learning } \\
\text { method to improve student physics learning outcomes" aims to improve physics } \\
\text { learning outcomes in second semester of Informatics Education students on } \\
\text { material quantities and measurements. This type of research is a quantitative } \\
\text { type of experiment, with a population of Informatics Education students, the } \\
\text { research subject are semester } 2 \text { of Informatics Education taking } 46 \text { students } \\
\text { consisting of } 2 \text { classes there are } 2 A \text { and } 2 B \text {. The results of the study } \\
\text { experienced an increase in student physics learning outcomes with class } \\
\text { averages of } 76.25 \text { and } 75.65 \text {, previously at } 72.45 \text { and } 70.35 \text { of the average } \\
\text { value had increased by } 20 \% \text {. The application of the discussion method of group } \\
\text { buzz learning not only affects student learning outcomes but also motivation } \\
\text { and interest in learning increases because in this method teamwork is highly } \\
\text { prioritized, causing other group members to be active and courageous in } \\
\text { expressing opinions when taking responsibility for answers in front of the class } \\
\text { The use of this method can reduce the problems that exist especially in } \\
\text { learning physics on material quantities and measurements. }\end{array}$} \\
\hline $\begin{array}{l}\text { Keywords } \\
\text { Buzz Grup Discussion } \\
\text { Method, learning } \\
\text { outcomes, quantities and } \\
\text { measurements }\end{array}$ & \\
\hline InformasiArtikel & ak \\
\hline $\begin{array}{l}\text { SejarahArtikel } \\
\text { Diterima: Agustus } \\
\text { Direvisi: Oktober } \\
\text { Dipublikasi: Desember }\end{array}$ & \multirow{2}{*}{$\begin{array}{l}\text { Penelitian yang berjudul "Penerapan Metode pembelajaran Diskusi Buzz Grup } \\
\text { untuk meningkatkan hasil belajar fisika mahasiswa" bertujuan untuk } \\
\text { meningkatkan hasil belajar fisika mahasiswa Pendidikan Informatika smester } 2 \\
\text { pada materi besaran dan pengukuran. Jenis penelitian ini adalah kuantitatif } \\
\text { jenis eksperimen, dengan populasi mahasiswa Pendidikan Informatika, subjek } \\
\text { penelitiannya adalah semester } 2 \text { Pendidikan Informatika yang sedang } \\
\text { menempuh materi tersebut yang berjumlah } 46 \text { mahasiswa terdiri dari } 2 \text { kelas } \\
\text { yakni kelas } 2 \mathrm{~A} \text { dan } 2 \mathrm{~B} \text {. Hasil penelitian mengalami peningkatan pada hasil } \\
\text { belajar fisika mahasiswa dengan rata- rata kelas sebesar76.25 dan } 75.65 \text {, } \\
\text { sebelumnya sebesar } 72.45 \text { dan } 70.35 \text { darinilai rata- rata tersebut mengalami } \\
\text { peningkatan sebesar } 20 \% \text {. Penerapan metode pembelajaran diskusi buzz grup } \\
\text { tidak hanya mempengaruhi hasil belajar mahasiswa saja tapi motivasi dan } \\
\text { minat belajar pun meningkat karena dalam metode ini kerja sama tim sangat } \\
\text { diutamakan sehingga menyebabkan anggota kelompok yang lain harus aktif } \\
\text { dan berani dalam mengemukakan pendapat pada saat mempertanggung } \\
\text { jawabkan jawabannya di depan kelas. Penggunaan metode ini dapat } \\
\text { mengurangi permasalahan yang ada khusunya dalam pembelajaran fisika pada } \\
\text { materi besaran dan pengukuran. }\end{array}$} \\
\hline $\begin{array}{l}\text { Kata kunci } \\
\text { Metode Diskusi Buzz } \\
\text { Grup, hasil belajar, } \\
\text { besaran dan pengukuran. }\end{array}$ & \\
\hline
\end{tabular}

Sitasi: Ismatulloh, K., Syahidi, K. (2019). Penerapan Metode Pembelajaran Diskusi Tipe Buzz Grup Untuk Meningkatkan Hasil Belajar Mahasiswa. Kappa Journal, Pendidikan Fisika, FMIPA, Universitas Hamzanwadi. 3 (2), 79-82 


\section{PENDAHULUAN}

Pendidikan berkualitas harus berlandaskan tujuan yang jelas, sehingga dapat membawa perubahan kearah yang lebih baik. Pendidikan di Indonesia harus sesuai dengan tujuan pendidikan Nasional yang tertuang dalam UU Sistem Pendidikan Nasional No. 20 tahun 2003 yaitu; "Pendidikan Nasional bertujuan untuk berkembangnya potensi siswa agar menjadi manusia yang beriman dan bertakwa kepada Tuhan YME, berahlak mulia, sehat, berilmu, cakap, kreatif, mandiri, dan menjadi warga Negara yang demokratis, serta bertanggungjawab." Berdasarkan tujuan tersebut pendidikan diharapkan dapat mengembangkan potensi yang dimiliki siswa dan dapat membentuk pribadi yang baik. Kunci sukses suatu bangsa adalah SDM yang dimiliki suatu bangsa terutama generasi mudanya. Salah satu upaya untu kmeningkatkan SDM suatu bangsa adalah dengan memperbaiki mutu pendidikan karena merupakan suatu dasar pembentuk watak, mental, dan spiritual manuasia sehingga dapat dijadikan tolak ukur suatu bangsa.

Fisika adalah salah satu ilmu pengetahuan alam yang mempelajari tentang prilaku atau gejala alam secara sistematis. Fisika bagi seseorang dapat diartikan sebagai kesukaan atau kesenengan mental yang mengandung sifat ilmiah, guna untuk memahami gejala-gejala dan teknik alam serta jagat raya ini.

Permasalahan yang sampai saat ini masih dirasakan oleh peneliti di lapangan menyatakan bahwa proses pembelajaran fisika itu sulit, membosankan, dan membutuhkan konsentrasi penuh serta ekstra untuk memahami materinya. Inilah kasus yang sering peneliti temui selama melakukan proses belajar mengajar di dalam kelas, ditambah lagi dikarenakan bidang keilmuan mahasiswa Pendidikan Informatika yang diajarkan heterogen, maksudnya tidak semua berasal dari bidang keilmuan IPA pada saat SMA/MA dahulu melainkan dari berbagai jurusan. Kasus ini sudah berlangsung kurang lebih empat tahun terakhir ini, inilah salah satu penyebab rendahnya hasil belajar atau prestasi belajar pada mata kuiah fisika yang belum seuai dengan apa yang diharpkan.

Rendahnya prestasi belajar tidak hanya disebabkan oleh beberapa permasalahan diatas melainkan ada beberapa permasalahan yang bersifat vital yaitu metode dan media pembelajaran yang digunakan oleh tenaga pengajar/ dosen kebanyakan, dosen masih banyak menggunakan metode konvensional seperti ceramah sehingga mahasiswa hanya mendengar, mencatat, tanpa berfikir kreatif bahkan tidak menutup kemungkinan mahasiswa merasa jenuh dan bosan bahkan mengantuk. Ditambah lagi media yang dosen gunakan hanya berbantuan Power Point sederhana yang dipenuhi tulisan layaknya bacaan di koran maupun majalahmajalah. Hendaknya dosen menciptakan kegiatan belajar yang efektif dan menarik dengan cara menggunakan metode pembelajaran kooperatif tipe Buzz Grup dengan berbantuan media pembelajaran berbasis android atau Flash yang bisa menghidupkan suasana belajar. Ini salah satu cara menghidupkan kreatifitas mahasiswa di zaman globalisasi serba teknologi saat ini.

Menurut Sunaryo (1989:107), diskusi dengan menggunakan metode buzz grup adalah diskusi pada satu kelompok besar yang dibagi menjadi beberapa kelompok kecil, terdiri atas 3 sampai 4 orang. Tempat duduk diatur sedemikian agar mahasiswa dapat bertukar pikiran dan berhadapan muka dengan mudah. Diskusi diadakan di tengah- tengah pelajaran atau akhir pembelajaran dengan maksud menajamkan kerangka bahan pelajaran, memperjelas bahan pelajaran atau menjawab pertanyaan- pertanyaan. 


\section{METODE}

Jenis penelitian ini adalah penelitian kuantitatif jenis eksperimen. Penelitian kuantitatif merupakan jenis penelitian yang banyak menggunakan angka. Lokasi penelitian dilakukan di Universitas Hamzanwadi. Waktu penelitian pada bulan februari sampai april 2019. Populasi dalam penelitian ini adalah mahasiswa Pendidikan Informatika, sedangkan untuk sampelnya menggunakan mahasiswa Prodi Pendidikan Informatika yang sedang menempuh mata kuliah fisika yakni semester 2 yang berjumlah 46 orang terdiri dari dua kelas yakni 2A dan 2B. Penelitian ini bertujuan untuk melihat peningkatan hasil belajar fisika mahasiswa pada materi besaran dan pengukuran.

\section{HASIL DAN PEMBAHASAN}

Berdasarkan penelitian yang sudah dilaksanakan pada bulan februari-april 2019 pada mahasiswa semseter 2 Pendidikan Informatika, didapatkan peningkatan hasil belajar fisika dan motivasi mahasiswa dengan berbantuan metode diskusi buzz grup. Di semester sebelumnya peneliti menggunakan metode permainan diteruskan dengan tournamen namun metode tersebut tidak efektif dikarenakan mahasiswa jadi kurang fokus dan lebih banyak bermain dengan tim lain bahkan materi yang seharusnya dibahas tidak tersampaikan secara menyeluruh diakibatkan waktu habis karena bermain membahas yang lainnya. Untuk nilai rata- rata pada dua kelas di semester 2 dengan menggunakan metode diskusi buzz grup sebesar 76.25 dan 75.65, sedangkan dengan metode permainan tournament nilai rata- ratanya sebesar 72.45 dan 70.35. Hasil belajar fisika mengalami peningkatan sebesar $20 \%$ tidak terlalu signifikan, disamping itu juga motivasi terlihat jelas pada masing- masing anggota kelompok untuk turut membantu dalam memecahkan permsalahan yang diberikan oleh peneliti.

Peneliti harus benar- benar memahami karakter dan keinginan mahasiswa dalam mengikuti pembelajaran khususnya fisika yang notabene menyebabkan cepat bosan dan sering mengalami kesulitan dikarenakan banyaknya rumus- rumus dan harus menghafalkan satuan dan simbol- simbol untuk meningkatkan ketertarikan dan motivasi dalam belajar meningkat yang bertujuan untuk menambah pemahaman mahasiswa. Selain itu juga peneliti harus bisa menyesuaikan metode yang tepat untuk pembelajaran fisika. Metode buzz grup dianggap cocok dalam menyikapi permasalahan- permasalahan yang muncul dalam materi besaran dan pengukuran dikarenakan dalam metode ini kerja tim benar- benar di fokuskan, kalau ada salah satu anggota tim yang malas maka akan menyebabkan timnya tertinggal jauh dengan tim lainnya.

\section{KESIMPULAN}

Kesimpulan yang dapat peneliti ambil dari hasil penelitian ini adalah adanya peningkatan dari hasil belajar fisika mahasiswa di semester 2 Prodi Pendidikan Informatika dengan menggunakan metode Buzz Grup dibandingkan dengan metode sebelumnya yakni games Tournament, mengalami peningkatan sebesar 20\%. Selain hasil belajar, motivasi dan minat belajar fisika mahasiswa mengalami peningkatan, disamping itu pula mahasiswa aktif untuk mencari refrensi yang lebih banyak untuk memecahkan permasalahan yang diberikan oleh dosen.

\section{SARAN}

Peneliti berharap kepada dosen atau tim pengajar khususnya pembelajaran fisika agar lebih berinovatif dan variatif dalam memilih metode pembelajaran guna untuk meningkatkan hasil belajar, minat, motivasi, dan keaktifan mahasiswa/siswa. Semoga dalam penelitian- 
penelitian selanjutnya tidak ditemukan lagi hambatan- hambatan seperti kurangnya sarana dan prasarana penunjang pembelajaran fisika khususnya di Prodi Pend.Informatika.

\section{UCAPAN TERIMA KASIH}

Terimakasih peneliti ucapkan kepada bapak Kaprodi Pendidikan Informatika yang telah memberikan kesempatan dalam pengambilan data di kelas, rekan- rekan dosen, dan adik- adik mahasiswa Pendidikan Informatika khususnya semester 2 yang telah berkontribusi demi terselesainya penelitian ini.

\section{DAFTAR PUSTAKA}

Nana, Sudjana.(2006). Penilaian hasil belajar mengajar. Bandung: Remaja Rosdakarya.

Sugiyono. (2008). Metode penelitian pendidikan pendekatan kuantitatif, kualitatif, dan $R \& D$. Bandung: Alfabeta

Sugiyono. 2011. Statistika untuk Penelitian. Bandung: Alfabeta.

Suharjono, D. dan Sulistyo, B. (2017). Penerapan metode pembelajaran diskusi Buzz Grup untuk meningkatkan hasil belajar siswa. Jurnal pendidikan teknik otomotif edisi XIX No. 1

Suminah.(2013). "Peningkatan hasil belajar siswa dengan menerapkan metode diskusi buzz grup pada matapelajaran IPS kelas IV siswa sekolah dasar”.Jurnal penelitian guru sekolah dasar (Volume 1 No. 2 Tahun 2013). 